\title{
How social challenges affect children's regulation and assignment quality in hypermedia: a process mining study
}

\author{
Cindy Paans ${ }^{1}$ (D) $\cdot$ Erdem Onan $^{1} \cdot$ Inge Molenaar $^{1} \cdot$ Ludo Verhoeven $^{1} \cdot$ Eliane Segers $^{1,2}$
}

Received: 28 January 2019 / Accepted: 19 August 2019/Published online: 8 October 2019

(C) The Author(s) 2019

\begin{abstract}
The present study investigated the extent to which 18 dyads in 5th and 6th grade, who experienced low levels of social challenge, differed from 12 dyads who experience high levels of social challenge in terms of the quality of their written assignment, as well as the frequency and sequential pattern of their cognitive, metacognitive, relational, and off-task activities during a collaborative hypermedia assignment. Sequential analyses were performed by means of process mining with a fuzzy miner algorithm. Results showed that assignment quality was higher for low social challenge dyads. In addition, these more successful dyads showed more cognitive processing activities, more high-cognition, and fewer off-task activities. In terms of their process models, low and high challenge dyads showed marked differences. More specifically, high social challenge dyads showed a vicious cycle of social challenges and off-task behaviors, whereas low social challenge dyads engaged in high-cognition. In addition, for low challenge dyads, but not high challenge dyads, the various metacognitive activities were closely connected to each other. These findings indicate that social challenges not only affect assignment quality, but also fundamentally affect the overall learning process.
\end{abstract}

Keywords Process mining $\cdot$ Hypermedia $\cdot \mathrm{SSRL} \cdot$ Primary school $\cdot$ Collaborative learning

In today's classrooms, children are frequently asked to work together in pairs in open-ended learning environments. Often these are digital hypermedia environments. Hypermedia can provide children with flexible learning routes and dynamic content-information that consists of

Cindy Paans and Erdem Onan contributed equally to this work.

Cindy Paans

c.paans@psych.ru.nl

1 Behavioural Science Institute, Radboud University, Montessorilaan 3, 6525 HR Nijmegen, The Netherlands

2 Instructional Science, Twente University, Enschede, Netherlands 
multiple representations such as text, audio, and video (Azevedo and Cromley 2004). However, working and learning together in such complex environments is not an easy task for children, because dyad members not only have to regulate their own learning, but also have to focus on the collaborative process (Greene et al. 2011; Kirschner and Erkens 2013; Kreijns et al. 2013). In this view, socially-shared regulation of learning (SSRL) describes how children interdependently engage in cognitive, metacognitive, and relational activities to regulate group learning (Hadwin et al. 2011). However, social challenges between dyad members can affect children's engagement in SSRL (Rogat and Linnenbrink-Garcia 2011). Such challenges refer to communicative and relational issues between children, such as having opposing views on a topic, a failure to get along, or being highly critical of the other dyad member's contributions (Järvenoja and Järvelä 2009). While social challenges have been shown to negatively affect learning (Barron 2003), it is not yet clear how they relate to children's regulation of learning, both in terms of the frequencies of cognitive, metacognitive and relational activities, as well as their relative arrangement. Investigating these frequencies and relative arrangements (i.e., sequential patterns) may explain how multiple activities interact and thereby influence the overall learning process (Molenaar and Järvelä 2014; Reimann 2009). In the current study, we therefore investigated how social challenges affected dyad's quality of their written assignment as well as the frequencies and sequential patterns of their learning activities.

\section{Children's SSRL in hypermedia}

Working and learning together in hypermedia environments can be demanding for children, because of the non-linear and technology-rich nature of the learning environment (Azevedo and Cromley 2004). These environments offer a high degree of autonomy, but, as a result, also require students to exercise more control over their learning (Azevedo 2005; Azevedo and Cromley 2004). In addition, collaborative learning offers both opportunities and challenges for learners (Rogat and Linnenbrink-Garcia 2011; Ucan and Webb 2015). Simply having children perform a task together, does not automatically lead to productive collaboration (Khosa and Volet 2014).

It has been argued that a characteristic of successful collaborations is that dyad members engage in SSRL (Hadwin et al. 2011). SSRL can be defined as the collective and interdependently sharing of regulatory processes, beliefs, and knowledge, in order to arrive at a shared and coconstructed product or learning outcome (Hadwin et al. 2011; Panadero and Järvelä 2015). In their model on regulated learning in collaborative settings, Järvelä and Hadwin (2013), distinguish between three types of regulation. Firstly, during self-regulated learning the learners regulate their own learning independently of each other. Secondly, during co-regulation collaborating peers provide temporary support to each other's self-regulated learning. Finally, shared regulation (SSRL) is characterized by a shared task understanding and by collective goals and strategies. During SSRL, learners also engage in the shared regulation of motivation and emotions (Panadero and Järvelä 2015). All three forms of regulation have their place during collaborations, and may provide benefits, when adequately applied. For SSRL in particular, it was found that higher levels of SSRL have been related to better learning outcomes (Järvelä et al. 2016; Panadero and Järvelä 2015), whereas lower levels have been associated with lower satisfaction during the collaboration (Hadwin et al. 2011). SSRL is especially salient during the learning process when the task becomes more demanding, when challenges need to be resolved, or when activities need to be coordinated (Iiskala et al. 2011; Isohätälä et al. 2017). As such, SSRL may be important for explaining learning outcomes, motivational factors, and emotional factors. 


\section{The content space and relational space of learning}

While SSRL is a crucial component of collaborations, relatively little is known about which processes affect the quality of regulation in collaborative settings. Potentially relevant are social aspects of learning. In this light, a distinction has been made between two dimensions of learning, namely the content space and the relational space of learning (Barron 2003; Slof et al. 2010). These spaces may compete for the attention of the dyad and may affect each other (Barron 2003; Roy and Howe 1990). Below, we will first describe these two dimensions in more detail. In the next section, we will address how social challenges in the relational space may affect collaborative success.

The content space of learning contains discussions around the learning task (Barron 2003). In this space, cognitive activities are used to form a proper understanding of the knowledge domain, and metacognitive activities are used to monitor and regulate these cognitive activities (Slof et al. 2010). Cognitive activities can be divided into low-level cognitive processing and high-level cognitive processing (King 2002). Lowlevel cognitive processing (hereafter referred to as low-cognition) involves the processing of content-information, for example, with the aim of memorisation or simple application of the learning material. It helps learners to build a shared task understanding (Volet et al. 2009). In contrast, high-level cognitive processing (hereafter referred to as high-cognition) refers to cognitive activities, such as elaborating, making inferences, or asking questions, that enable the construction of new cognitive schemas, or a deeper understanding of the material (King 2002; Volet et al. 2009). While both types of cognitive activities are important for learning, especially highcognition has been related to better learning outcomes (King 2002; Molenaar and Chiu 2017). Metacognitive activities refer to the activities learners use to monitor and control their cognitive activities (Veenman et al. 2006). These activities include orienting oneself on the task, planning how to proceed with the assignment, monitoring progress and understanding, and evaluating the learning progress (Meijer et al. 2006; Veenman et al. 2006). As such, learners use these activities to achieve their learning goal and complete their (hypermedia) task or assignment. Both the frequency and the quality of metacognitive activities have been associated with better learning outcomes (e.g., Goos et al. 2002; Paans et al. 2018).

The relational space of learning contains challenges and opportunities that arise during social interactions (Barron 2003; Panadero and Järvelä 2015). Collaborating children have to engage in social and communicative activities, as well as in the regulation thereof (Rogat and Linnenbrink-Garcia 2011; Slof et al. 2010). These activities include supporting each other's contributions, planning and monitoring how to collaborate, and being respectful to each other (Barron 2003; Janssen et al. 2012; Rogat and Linnenbrink-Garcia 2011). While much SSRL research has focused on the execution of cognitive and metacognitive activities, which are both part of the content space of learning, the relational space is also important for explaining successful collaborative learning (Kreijins et al. 2003, 2002; Salonen et al. 2005). In fact, social interactions and cognitive activities have been found to be interdependent (Roy and Howe 1990). Therefore, taking into account the relational space may help to explain how groups arrive at socially sharing their cognitive and metacognitive activities and how they subsequently achieve better learning outcomes (Van den Bossche et al. 2006). 


\section{Social challenges and regulation of learning in dyadic tasks}

Within the relational space of learning, social challenges may arise (Rogat and LinnenbrinkGarcia 2011). Social challenges include a failure to get along, a lack of joint attention, being highly critical, using social comparisons, unbalanced levels of participation or contributions to the regulation of learning, and keeping one's own contributions central to the learning product (Järvenoja and Järvelä 2009; Rogat and Adams-Wiggins 2015). If children focus too narrowly on their own thoughts and contributions, this may leave little room for negotiating a different perspective (Barron 2003). Consequently, social challenges may affect the quality of the learning process, occurrences of cognitive and metacognitive activities, and learning outcomes. Such social challenges may be particularly difficult for dyads, compared to larger groups, because dyads dissolve more quickly upon disengagement or disagreement, and emotions tend to be stronger (Moreland 2010).

Social challenges may affect the quality of the learning process and the extent to which SSRL occurs. Frequent negative utterances negatively affect interactions, and subsequently the dyad's learning (Barron 2003). For example, rudeness and disruptive communication decreases the likelihood by which high-school students arrive at correct solutions during problem solving (Chiu and Khoo 2003). Equally, groups with a negative group climate have more difficulty adapting under time pressure (Bakhtiar et al. 2018). In sixth-graders, disagreements and arguments affected the quality of shared learning activities and reduced the learners' engagement in on-task behaviours (Rogat and Linnenbrink-Garcia 2011). Social challenges may thus result in resistance within the dyad and put an end to collective task engagement (Bakhtiar et al. 2018). In turn, the occurrence of SSRL becomes rare once one member becomes disengaged (Isohätälä et al. 2017). Consequently, negative interactions have been related to lower quality regulation among collaborating peers (Rogat and Adams-Wiggins 2014).

Social challenges may not only increase negative interactions and disengagement, but may also result in fewer positive interactions overall, by affecting the group climate (see also Bakhtiar et al. 2018). Positive social interactions include activities such as attentive listening, respectful communication, and mutual participation (Ucan and Webb 2015). Additionally, new ideas and proposals are discussed or accepted (Barron 2003; Rogat and Adams-Wiggins 2015). As such, positive interactions appear to facilitate the occurrence of SSRL, as well as its quality (Rogat and Linnenbrink-Garcia 2011; Ucan and Webb 2015; Volet et al. 2009). They have also been related to better learning outcomes (Barron 2003). For example, they have been found to support the emergence of low-cognition (Molenaar and Chiu 2014).

It has been suggested that successful dyads are able to overcome social challenges during learning (Hadwin et al. 2011). When conflicts arise during collaboration, interpersonal disagreements can lead to intellectual development in the group or dyad (Levine and Resnick 1993). Additionally, constructive conflict has been related to the development of shared mental models, which in turn has been associated with improved task performance (van den Bossche et al. 2011). However, conflict is potentially more difficult in children. At least in young children, research suggests that conflict may actually result in worse performance (Tudge 1989, 1992). The hallmark of constructive conflict is that dyad members evaluate each other's contributions critically, consider each other's ideas and differences in opinion seriously, and are able to speak openly (van den Bossche et al. 2011). These results suggest that the effect of social challenges on learning does not lie in the frequency of social challenges, but in how the learners resolve these challenges. Therefore, part of the quality of the learning process is revealed by how social challenges and cognitive and metacognitive activities are sequentially embedded in the learning process as a whole. 


\section{Sequential variations in SSRL}

While research has shown that social challenges affect the learning outcomes of collaborating individuals, so far, little research has analyzed how social challenges affect the sequential order of activities in the learning process. This sequential order of the activities is relevant for understanding how students use SSRL to guide their learning. Furthermore, because it has been suggested that the quality of regulation is more important for learning than its frequency (de Jong et al. 2005), the temporal unfolding of learning activities over time needs to be understood (Järvelä et al. 2016). At a practical level, sequential analyses will show how one can differentiate between challenges that are successfully resolved, and challenges that require the involvement of a teacher to help the dyad get back on task.

Specifically for (S)SRL, studies that incorporate time and the sequence of events have been fairly limited. Two methods have been used most frequently, namely discourse analysis and process mining (e.g., Chiu and Fujita 2014; Günther and van der Aalst 2007). Both analytical methods investigate temporal and sequential characteristics of events. Two studies used statistical discourse analysis to examine the sequential pattern of learning activities in primary school children (Molenaar and Chiu 2014, 2017). These two studies investigated how sequences of cognitive, metacognitive and relational activities affected subsequent cognition in primary school children (Molenaar and Chiu 2014), and how sequential patterns leading to cognitive activities affected group performance (Molenaar and Chiu 2017). Their analyses indicated that positive interactions, as well as metacognitive planning and monitoring activities could set the stage for cognitive activities. Negative interactions, on the other hand, reduced the chance that high-cognition occurred (Molenaar and Chiu 2014). In turn, cognitive activities were related to learning outcomes. Low-cognition on its own predicted essay length, whereas high-cognition on its own predicted essay quality (Molenaar and Chiu 2017). When lowcognition occurred in the context of other (either low or high) cognitive activities, however, it too had a positive effect on essay quality. This shows that the sequential context in which learning activities take place influences their effect on overall learning outcomes.

Process mining is also used to investigate differences in learning processes, especially between two distinct groups of students (Bannert et al. 2014; Sobocinski et al. 2017) For example, Sobocinski et al. (2017) showed differences between learning sessions that learners estimated to be high or low in terms of cognitive, motivational, and emotional challenges. Bannert et al. (2014) showed that successful and less successful students differed from each other in terms of their learning process. Successful students used more diverse metacognitive activities, including analysis (i.e., orientation, planning, and goal specification), monitoring, and evaluation. Their analyses activities were connected to both monitoring and evaluation in the process model. For less successful students, however, the process model displayed no evaluation activities and showed no connections between analysis and monitoring. Similarly, using sequence pattern mining, Kinnebrew et al. (2014) found that high performing 8th grade students monitored their task understanding more when they made an erroneous attempt in an open-ended learning environment than their low performing counterparts. Subsequently, they were more likely to attempt to correct their mistakes (Kinnebrew et al. 2014).

Hence, both process mining and statistical discourse analysis have been used previously to unravel sequential patterns in SSRL. Process mining may be an especially relevant analytical method to analyze the differences between the learning processes of groups experiencing high and low levels of social challenge during collaborations. While statistical discourse analysis offers insight into the sequential patterns of activities, process mining shows the relations 
between the various activities in the process as a whole. In addition, process mining structures and simplifies process data in such a way that an understandable and clear representation of the learning process emerges (Günther and van der Aalst 2007). One type of process mining, that has been used before in this type of research (Bannert et al. 2014; Schoor and Bannert 2012), is referred to as Fuzzy Mining. It amplifies the most relevant and dominant sequences in the process model and removes weaker connections between activities (Günther and van der Aalst 2007). The resulting patterns are displayed in a roadmap-like process model that consist of nodes (events) and edges (relations between events). Based on two principal concepts, significance and correlation, Fuzzy Mining decides which nodes and edges are displayed and how they are organized in the process model (Günther and van der Aalst 2007). Significance indicates the relative importance of an event or sequence in the model. This importance can be measured by the frequency of their occurrence. In addition, for the significance of events, significance is also measured by the importance of the node for directing the process to another node (i.e., routing significance). Correlation indicates how closely related two consecutive events are in terms of their data attributes (Günther and van der Aalst 2007). The result is a simplified model of the learning process in which the relative arrangement of the various activities is shown. As such, Fuzzy Mining can show how social challenges are positioned in the larger learning process. A comparison between dyads with more versus fewer social challenges can show how differences in social challenges affect cognitive, metacognitive, relational activities, and off-task and their sequential relationship. Fuzzy Mining can show the antecedents of challenges, as well as how learners respond to these challenges once they arise.

\section{The present study}

In conclusion, the aim of the current study was to examine how social challenges affect collaborative learning processes and outcomes of primary school children during a dyadic hypermedia assignment. For this purpose, three research questions were addressed:

RQ 1: To what extent do low and high social challenge dyads differ in the quality of their written assignment?

RQ 2: How do low and high social challenge dyads differ in terms of the frequency of their cognitive, metacognitive, relational, and off-task activities?

RQ 3: How do low and high social challenge dyads differ in terms of the sequential pattern of their cognitive, metacognitive, relational, and off-task activities?

In order to answer these questions, children participated in a dyadic hypermedia assignment on the subject of the heart and living a healthy lifestyle. Their verbal interactions during the collaboration were transcribed and coded, based on which dyads with low and high levels of social challenge were distinguished. The hypotheses were that low challenge dyads would show higher assignment quality (e.g., Barron 2003; Chiu and Khoo 2003), more highcognition (e.g., Bakhtiar et al. 2018; van den Bossche et al. 2011), more metacognitive activities (e.g., Rogat and Adams-Wiggins 2014), and fewer off-task activities (e.g., Rogat and Linnenbrink-Garcia 2011) than high challenge dyads. In terms of the sequential patterns, no a priori hypotheses were formulated. 


\section{Method}

\section{Participants}

Participants were 60 5th an 6th grade children, making up 30 randomly assigned same-sex dyads ( 12 boy and 18 girl-dyads) from six different schools in the Netherlands. Of these dyads, 18 had low levels of social challenge, and 12 had high levels of challenge (see Analyses section below). Their age ranged from 10 to 12 years $(\mathrm{M}=10$ years, 9 months; $\mathrm{SD}=$ 7.8 months). The sample was predominantly Dutch. In total, $80.0 \%$ of all participants had two Dutch parents, and $86.7 \%$ reported that Dutch was the first home language. Recruitment took place by letter, distributed by the schools. This sample was selected from a larger sample of 88 dyads (Paans et al. 2019). Only 30 dyads were included because of the timeintensiveness of transcribing and coding the videos. Dyads were selected such that all schools were represented proportionally to the number of participants from that school and equal numbers of dyads with low, medium, high, or unequal learning gain on a declarative knowledge test (see Prior knowledge measure below) were included in the sample.

\section{Materials}

Hypermedia environment In the present study, a WebQuest environment was used to teach on the subject of the heart and healthy living. A WebQuest is a sheltered Internet environment in which the teacher can structure and organize the learning process through predefined instructions and resources (Segers and Verhoeven 2009). In the current WebQuest, children were asked to collaboratively write a text of 300 words about the functions of the heart and how to keep the heart healthy, that could be understood by 3rd grade students. The length of 300 words was chosen to ensure that the assignment was sufficiently challenging and required learners to spend some time working on it. The third-grade audience was chosen, so that learners were encouraged to use higher cognitive processing. It required them to adjust the text from the website, by giving examples, simplifying or explaining the terms they used, or to summarize lengthy passages. As such, it required them to collaborate, and to share and coconstruct knowledge. The quality of the text they wrote during this assignment was later analysed as a measure of learning (see Assignment quality).

For the purpose of this assignment, the children could use nine Web pages that presented the learning content through texts and images, and that contained links to four short videos. In a menu on the left of the screen, the WebQuest contained links to: an introduction page, an assignment page where the assignment was explained; a roadmap page where the assignment was structured into several steps; a resources page that contained the links to the 9 content pages; a review page where children could evaluate their work; and a conclusion page. In addition, there was a link to a worksheet, where the assignment could be written. Children could navigate through the website via in-text hyperlinks and the navigation menu.

Prior knowledge Prior knowledge of the participants was measured using a two-part declarative knowledge test. In the first part, children had to match 14 words to explanatory sentences. For example, 'red blood cell' had to be connected to 'brings oxygen to every part of the body'. In the second part, children had to label 10 parts in two pictures of the heart and the circulatory system. The names of the parts were presented in random order. For example, children had to locate the 'left atrium' in the picture of the heart. Children were given $15 \mathrm{~min}$ for the first task, 
and $10 \mathrm{~min}$ for the second. Both were introduced with a worked-out example that the test leader went through together with the class. Internal consistency was moderate for the connecting part $(\alpha=.61)$ and sufficient for the labelling part $(\alpha=.74)$.

Verbal interactions During the WebQuest assignment, the verbal utterances within dyads were video-recorded. These utterances were segmented and coded with the coding scheme created by (Molenaar et al. 2011; Table 1). This coding scheme had mutually exclusive mainand sub-categories for each conversational turn. Turns were segmented when the focus of the topic changed, the speaker changed, or both dyad members were silent for longer than $2 \mathrm{~s}$. The current study did not code SSRL episodes, but only coded activities at the level of individual turns. As such, the coding could distinguish between cognitive and metacognitive activities, but not between self-regulation, co-regulation, or shared regulation of learning. The transcripts of five dyads (3063 turns; 16\% of total turns) were coded by a trained second coder to establish interrater reliability. Reliability was excellent for main categories $(K=.90)$ and subcategories (K's ranged from .88 to .97).

Table 1 Final main and sub categories of verbal interactions

\begin{tabular}{|c|c|c|c|}
\hline Main code & Sub-category & Description & Examples \\
\hline \multirow[t]{5}{*}{ Cognition } & Reading & $\begin{array}{l}\text { Turns in which the participant is } \\
\text { reading from the WebQuest }\end{array}$ & $\begin{array}{l}\text { "The heart is a strong muscle, } \\
\text { approximately the size of your } \\
\text { fist" }\end{array}$ \\
\hline & Processing & $\begin{array}{l}\text { Turns in which the participating is } \\
\text { writing or memorizing learning } \\
\text { content }\end{array}$ & $\begin{array}{l}\text { "There are three types of blood } \\
\text { cells" }\end{array}$ \\
\hline & High-cognition & $\begin{array}{l}\text { Turns about the content that go deeper } \\
\text { than reading or processing (e.g., } \\
\text { elaboration, questioning, }\end{array}$ & $\begin{array}{l}\text { Elaboration: "So, the platelets } \\
\text { made the heel when I fell last } \\
\text { week" }\end{array}$ \\
\hline & & summarizing) & $\begin{array}{l}\text { Questioning: "Okay, but what do } \\
\text { the coronary arteries do?" }\end{array}$ \\
\hline & & & $\begin{array}{l}\text { Summarizing: "So, the blood picks } \\
\text { up oxygen in the lungs and then } \\
\text { brings it back to the heart" }\end{array}$ \\
\hline \multirow[t]{3}{*}{ Metacognition } & Analysis & $\begin{array}{l}\text { Turns in which participants orient } \\
\text { themselves to the task, or make a } \\
\text { plan }\end{array}$ & $\begin{array}{l}\text { Orientation: "What is a } \\
\text { worksheet?" } \\
\text { Planning: "Let's write that down!" }\end{array}$ \\
\hline & Monitoring & $\begin{array}{l}\text { Turns in which participants judge } \\
\text { their own understanding or } \\
\text { progress }\end{array}$ & $\begin{array}{l}\text { "I don't understand this" } \\
\text { "We need to hurry!" }\end{array}$ \\
\hline & Evaluation & $\begin{array}{l}\text { Turns in which participants judge } \\
\text { whether they achieved their goal, } \\
\text { or what they would differently next } \\
\text { time }\end{array}$ & $\begin{array}{l}\text { Evaluation: "We wrote a good } \\
\text { assignment." } \\
\text { Reflection: "We wasted time } \\
\text { watching all those videos" }\end{array}$ \\
\hline \multirow[t]{3}{*}{ Relational } & Social challenge & $\begin{array}{l}\text { Turns that indicate disagreement or } \\
\text { rejection of their partner's ideas, or } \\
\text { in which participants try to create } \\
\text { more engagement with the task }\end{array}$ & $\begin{array}{l}\text { Rejection: "That's wrong!" } \\
\text { Engagement: "Stop doing that!" }\end{array}$ \\
\hline & Support & $\begin{array}{l}\text { Turns that indicate agreement or } \\
\text { support of their partner's ideas }\end{array}$ & "Good idea!" \\
\hline & Task division & $\begin{array}{l}\text { Turns in which participants discuss } \\
\text { who performs (part of) a task }\end{array}$ & "I want to type now!" \\
\hline Off-task & Off-task & Turns that are irrelevant to the task & $\begin{array}{l}\text { "What will you be doing } \\
\text { upcoming weekend?" }\end{array}$ \\
\hline
\end{tabular}


All utterances were initially coded according to the original coding scheme, but we focused on cognitive, metacognitive, relational, and off-task activities for the purpose of this study. Cognitive activities included the sub-categories reading, processing, elaboration, questioning, and summarizing; metacognitive activities consisted of orientation, planning, monitoring, evaluation, and reflection; and relational activities were support, rejection, engagement, and task-division. Finally, all the utterances that were not relevant to the task were coded as off-task activities. In terms of social challenges, it should be noted that, if dyad members only voiced a rejection of their partner's idea, it was coded as social challenge. However, if dyad members referred to the content, for example, by giving a reason for their rejection, it was coded as metacognitive evaluation.

To ensure the data fitted the requirements for process mining, we combined some subcategories and excluded others. This reduced the effects of sub-categories with considerably low frequencies on the process mining results ( $<10$ occurences; see also Bannert et al. 2014; Sobocinski et al. 2017). First, we checked whether these low-occurring activities were correlated with another sub-category. Whenever this was the case, it was considered whether it made sense theoretically to combine the correlated activities. Categories that met these criteria were combined, whereas those that did not were removed from the analyses. This resulted in the following changes. For cognitive activities, elaboration, questioning, and summarizing were combined into High-Cognition (Molenaar and Chiu 2017). For metacognitive activities, orientation and planning were combined into Analysis, as they are both related to the forethought phase of self-regulated learning (Zimmerman 2002). Additionally, evaluation and reflection were combined into Evaluation, as they are both related to the self-reflection phase (Zimmerman 2002). In relational activities, rejection and engagement were combined into Social Challenge, because earlier research showed that positive social climate among dyad members is threatened by students' failure to get along, frequently opposing views on the topic, and lack of joint attention (Barron 2003; Rogat and Linnenbrink-Garcia 2011). Finally, task-division was excluded because its frequency of occurrence was too low and correlations were not high enough to justify combining it with other sub-categories.

Assignment quality The quality of the dyads' writing assignments was assessed with a predefined list of 50 terms and explanations describing the function of different parts of heart, the circulatory system, blood-cell types, and healthy living. Two independent raters scored the quality of the assignments and interrater agreement was high (intraclass $r=.97$ ).

\section{Procedure}

The present study is part of a larger research project that focused on children's collaborative hypermedia learning. Data was collected on their executive functions, social relations, motivation, collaboration satisfaction, navigation activities, verbal interactions, and learning outcomes. Only aspects relevant to the current study will be described.

Data collection started with a classroom session. In this session, participants received a short presentation that introduced the WebQuest environment and assignment. In addition, they performed the prior knowledge test.

The WebQuest took place outside the classroom. Participants were first shortly reintroduced to the WebQuest, to ensure they understood what they had to do, and to provide 
an opportunity to ask questions. The children performed the assignment in same-sex dyads and had 45 min to complete it. They were allowed to finish early. However, dyads who informed the test leader that they finished the assignment within the first 30 min were asked to reread the assignment page, and reflect on whether their assignment met the requirements. While children were working together, they were periodically reminded of the time they had left to finish the assignment. These notifications took place after 15, 30, and $40 \mathrm{~min}$. Test leaders did not answer any questions about the learning content, but did answer questions about the use of the WebQuest environment and the meaning of words. During the assignment, the interactions between dyad members were video-recorded for later analysis. Upon finishing, they received a small gift for participating.

\section{Analyses}

Low and high social challenge Low and high social challenge groups were distinguished as follows. First, the relative frequency of the verbal activities that were coded as social challenge was calculated. Relative frequencies were used because of the large differences between dyads in their absolute number of conversational turns. Next, these relative frequencies were transformed into z-scores. A z-score of 0 was used as the cut-off value to dichotomize the variable. That is, all dyads showing frequencies below 0 were seen as low social challenge dyads $(n=18)$, whereas dyads that scored above 0 were seen as high social challenge dyads $(n=12)$. To check if these two groups indeed differed in terms of their relative level of social challenge, an independent samples t-test was performed. The result showed that high challenge groups $(M=.09, S D=.03)$ indeed had higher levels of challenge than low challenge groups $(M=.03, S D=.01), t(12.98),=6.78, p<.001, d=2.71$. Groups were similar in terms of their gender, $\chi^{2}(1)=2.80, p=.094$. Furthermore, group differences between low and high challenge groups were not due to differences in prior knowledge. For both groups, the mean dyadic level of prior knowledge was similar, $t(28)=.12, p=.903$, and showed equal variances, $F$ $(28)=.76, p=.391$. In addition, the difference between dyad member's prior knowledge within each dyad was similar in both groups, $t(28)=.15, p=.885$.

Research questions 1 and 2 In order to answer the first research questions - to what extent do low and high social challenge dyads differ in terms of the quality of their written assignment - an ANCOVA was performed, with social challenge as the independent variable, assignment quality as the dependent variable, and prior knowledge as a covariate. Assignment quality was a collaborative measure, but prior knowledge was tested individually. Therefore, the mean level of prior knowledge of both dyad members was used as a covariate. Individual levels of prior knowledge were not used, because of the low sample size.

In order to answer the second research question - how do low and high social challenge dyads differ in terms of the frequency of their cognitive, metacognitive, relational, and off-task activities - several Mann-Withney $U$ tests were performed, with social challenge as the independent variable, and the various learning activities as the dependent variables.

Fuzzy miner In order to investigate the third research question - How do low and high social challenge dyads differ in terms of the sequential pattern of their cognitive, metacognitive, relational, and off-task activities? - the data was analysed using the Fuzzy Miner process mining algorithm and the ProM 6.7 software. 
Parameter settings for fuzzy miner Within the ProM software, the process models generated by Fuzzy Miner can be further simplified with three parameters: utility ratio, edge cut-off and node cut-off. Values for these parameters were based on standard settings and earlier research that used this method (Bannert et al. 2014).

For removing edges, the model measures both the significance and correlation of each edge. The utility ratio then determines the relative weight significance and correlation have in establishing the importance (i.e., utility) of the edges. The current utility ratio was set at .75, which indicates that more weight was given to the significance of the edges relative to their correlation. The edge cut-off then determines the threshold value for the utility of each edge. The current edge cut-off was set at .20, indicating that the utility of each edge had to reach at least .20 for the edge to be included in the model.

For removing nodes, the node cut-off is the threshold value that determines the level of significance (unary significance) a node should have to be included in the model. If the significance is below this threshold it is either removed from the model, or clustered together with other nodes that show low levels of significance, but are correlated with the node in question. The current node cut-off value was set at .25.

Other settings that were used in ProM were the following. First, attenuation indicates that the effect of events closer to each other have a stronger effect on the measurement than those further apart. Linear attenuation was used, which means that the effect of events decreased linearly with distance. Second, the originator correlation was set to not active. This setting allows for choosing to emphasize either sequences within one dyad member or sequences between dyad members. However, the current data mostly showed sequences in which the dyad members followed up on each other, making the setting superfluous.

\section{Results}

\section{The effect of social challenge on assignment quality}

In order to investigate the extent to which low and high social challenge dyads differed in terms of their assignment quality, an analysis of covariance (ANCOVA) was performed that controlled for the mean prior knowledge in the dyad. Results showed that low social challenge dyads $(M=21.17 ; S D=8.95)$ scored higher on assignment quality than high social challenge dyads $(M=14.50 ; S D=6.63), F(1,27)=6.17, p=.019, \eta^{2}=.186$. This indicates that, while taking prior knowledge into account, assignment quality is higher in low social challenge dyads compared to high social challenge dyads.

\section{The effect of social challenge on the frequency of learning activities}

Table 2 shows the relative frequencies of the final categories of the verbal interactions, and prior knowledge and assignment quality for low and high social challenge dyads separately. The absolute frequencies of the verbal interactions are displayed in Appendix Table 7. In order to investigate the extent to which low and high social challenge dyads differed in terms of the relative frequency of their cognitive, metacognitive, relational, and off-task activities, several Mann-Withney $U$ tests were performed. The results indicated that cognitive processing was more frequent for low challenge dyads $(M d n=27.18)$ than for high challenge dyads $(M d n=$ 
Table 2 Relative frequencies of coded verbal interactions in low- and high-challenge dyads

\begin{tabular}{|c|c|c|c|c|c|c|c|c|}
\hline & \multicolumn{4}{|c|}{ Low challenge $(n=18)$} & \multicolumn{4}{|c|}{ High challenge $(n=12)$} \\
\hline & Min & Max & M & SD & Min & Max & M & $\mathrm{SD}$ \\
\hline \multicolumn{9}{|l|}{ Cognition } \\
\hline Reading & .03 & .30 & .18 & .07 & .04 & .29 & .14 & .07 \\
\hline Processing & .02 & .64 & .29 & .13 & .09 & .34 & .21 & .06 \\
\hline High-cognition & .00 & .12 & .04 & .03 & .00 & .05 & .02 & .02 \\
\hline \multicolumn{9}{|l|}{ Metacognition } \\
\hline Analysis & .04 & .15 & .08 & .03 & .05 & .11 & .08 & .02 \\
\hline Monitoring & .11 & .32 & .22 & .05 & .13 & .40 & .24 & .08 \\
\hline Evaluation & .01 & .11 & .04 & .03 & .01 & .08 & .03 & .02 \\
\hline \multicolumn{9}{|l|}{ Relational } \\
\hline Challenge & .01 & .05 & .03 & .01 & .06 & .15 & .09 & .03 \\
\hline Support & .00 & .13 & .07 & .03 & .03 & .09 & .05 & .02 \\
\hline \multicolumn{9}{|l|}{ Other } \\
\hline Off-task & .00 & .22 & .04 & .05 & .04 & .24 & .11 & .06 \\
\hline Mean prior knowledge & 3.50 & 13.25 & 10.03 & 2.62 & 4.00 & 14.50 & 9.90 & 3.21 \\
\hline Assignment quality & 4 & 37 & 21.17 & 8.95 & 6 & 28 & 14.50 & 6.63 \\
\hline
\end{tabular}

20.84), $U=53, Z=2.33, p=.019, r=.43$. High-cognition was also more frequent for low challenge dyads $(M d n=4.02)$ than high challenge dyads $(M d n=1.99), U=60.5, \mathrm{Z}=2.01, p=$ $0.044, r=.37$. In contrast, off-task activities were more frequent for high challenge dyads $(M d n=09.12)$ than for low challenge dyads $(M d n=2.71), U=29, Z=3.34, p=.001, r=.61$. Reading, supporting, and metacognitive activities did not differ between the two groups. Summarizing, low social challenge dyads verbalized more cognitive processing and highcognition, whereas high social challenge dyads verbalized more off-task activities.

\section{Process models for low and high social challenge dyads}

In order to investigate the sequential patterns of cognitive, metacognitive, relational, and off-task activities of low and high social challenge dyads, process mining was performed. Tables 3, 4, 5 and 6 show examples of the coded interactions that were used as input for the process models. Figure 1 shows the process model of low challenge dyads. The numbers in the nodes represent the level of significance (i.e., importance of the node), the top numbers on the edges also represent the level of significance (i.e., importance of the edge), and the bottom number on the edge represents the correlation (i.e., how closely related events are) between the

Table 3 Extract of the effects of social challenge in low social challenge dyads

\begin{tabular}{llll}
\hline Speaker & Phrase & Main- code & Sub- code \\
\hline Lisa & Your cap, what was it again? & Metacognition & Monitoring \\
Lisa & Capillaries, right? & Metacognition & Monitoring \\
Lisa & *Inaudible* & Not-codable & Rejection \\
Emma & No & Relational & Planning \\
Emma & We could also browse some more, & Metacognition & Support \\
Lisa & because there are two more sources. & Relational & Reading \\
Lisa & Yes & Cognition &
\end{tabular}


Table 4 Extract of the effects of social challenge in high social challenge dyads

\begin{tabular}{llll}
\hline Speaker & Phrase & Main- code & Sub- code \\
\hline Mandy & Be quiet now *..* & Relational & Engagement \\
Jill & Enlarge the screen & Procedural & Learning task \\
Jill & Was that everything already, sir? & Metacognitive & Monitoring \\
Jill & Sorry, I think that was very funny & Metacognitive & Evaluation \\
Jill & Do you want my number? & Off-task & \\
Jill & Five, two, *..., Call me. & Off-task & \\
Jill & Five, two, three & Off-task & Engagement \\
Mandy & No, stop. I should quickly *...* & Relational & \\
Jill & Five, two, three & Off-task & Rejection \\
Jill & Nine, two, seven, call me okay? & Off-task & Relational \\
Mandy & No, don’t do that, all right? & Off-task & Read \\
Jill & Call, call & Cognitive & Evaluation \\
Mandy & You know, the heart of a mouse beats & Metacognitive & Rejection \\
Jill & We've already read everything. We're done. & Relational & \\
Mandy & Not at all. & &
\end{tabular}

two nodes. The conformance of this model was good. A measure of conformance is similar to the notion of explained variance, as it gives an estimate regarding the extent to which the fitted model represents the original data. When comparing the original event logs to the model, on average $77.22 \%(S D=6.76 \%)$ of the direct event sequences (that is, for two consecutive events) were represented by the model. For all individual dyads, conformance ranged between $61.54 \%$ and $90.26 \%$.

Looking at the relationships between sub-categories within each main category, the process model shows one-directional relationships between the cognitive activities. More specifically, reading leads to both high-cognition and processing, and high-cognition leads to processing. In terms of metacognitive activities, analysis and evaluation are clustered together by the process model, because of the low significance of and high correlation among the individual nodes. This analysis*evaluation cluster has a bi-directional relation with monitoring. This shows there is a high interaction between the various metacognitive activities. With respect to relational activities, the model shows no relations between the sub-categories. Secondly, looking at the relations between sub-categories across the various main categories, the model shows that processing leads to either monitoring or social challenge. Monitoring can feed back to processing, or move on to analyses*evaluation. Social challenge also leads to analysis*evaluation, from which

Table 5 Extract of the relations between analysis and support in low social challenge dyads

\begin{tabular}{llll}
\hline Speaker & Phrase & Main- code & Sub- code \\
\hline Lisa & 72,3 more words & Metacognition & Monitoring \\
Emma & Shall we just start with the next one? & Metacognition & Planning \\
Lisa & All right. & Relational & Support \\
Emma & Uhm & Not-codable & \\
Lisa & Okay, and after that we should...? & Metacognition & Monitoring \\
Emma & Uhm & Not-codable & \\
Lisa & "Your blood in the rollercoaster" & Metacognition & Planning \\
Emma & Yes. & Relational & Support \\
Lisa & "Day and night, your heart pumps blood through your body" & Cognition & Reading \\
\hline
\end{tabular}


Table 6 Extract of the relations between analysis and support in high social challenge dyads

\begin{tabular}{llll}
\hline Speaker & Phrase & Main- code & Sub- code \\
\hline Tim & Just copy it. & Metacognition & Planning \\
Max & Yes. & Relational & Support \\
Tim & All of it & Metacognition & Planning \\
Max & Yes. & Relational & Support \\
Max & Good plan. & Relational & Support \\
\hline
\end{tabular}

there are multiple pathways. The first pathway leads to monitoring, which could either go back to analysis*evaluation, or move on to processing. The second pathway leads to support, and then to reading, which is the only predecessor of high-cognition. Finally, there is a one-drectional path from high-cognition to support. Summarizing, the verbal interactions of low challenge dyads can be characterized by strong relations between processing, monitoring and analysis*evaluation. In addition, relational activities play a distinct role. While social challenge leads to analyses*evaluation, support leads to reading, and then on to high-cognition or processing.

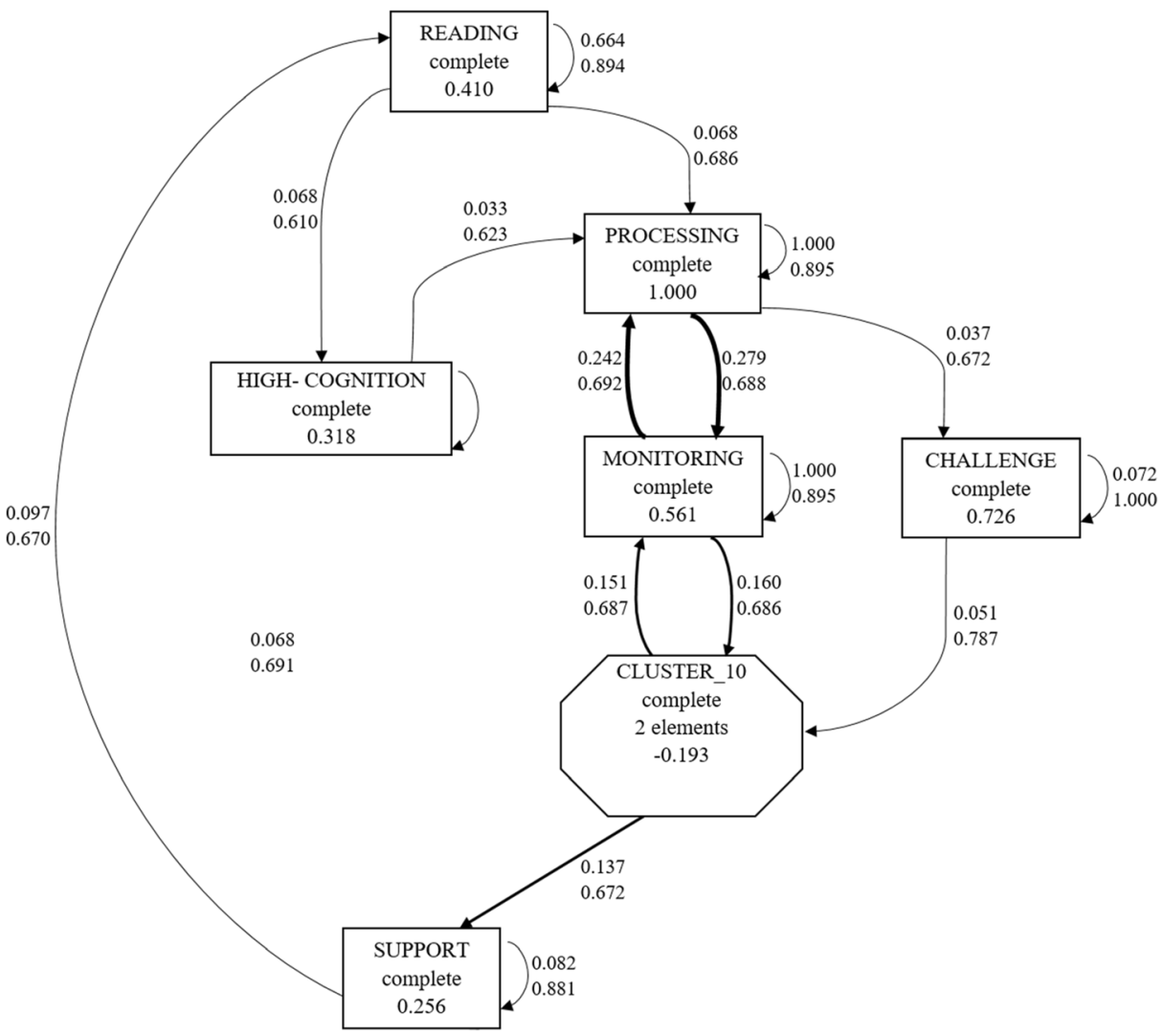

Fig. 1 Process model of low social challenge dyads. Cluster 10 consists of the elements Analysis and Evaluation. Numbers in the nodes represent the level of significance (the cluster shows the mean significance of the elements). Numbers on the edges represent the level of significance (top) and correlation (bottom) 
Figure 2 shows the process model of high challenge dyads. The conformance of this model was somewhat lower than that of low challenge dyads. On average, $62.85 \%(S D=12.33 \%)$ of event sequences of the original log could be replayed successfully, based on this model. For all but two dyads, conformance was higher than 50\%. Looking at the relations between subcategories within each main category, the model shows that for cognitive activities, reading has a one-directional pathway to processing. High-cognition did not reach the significance cutoff value and was therefore not included in the process model. For metacognitive activities, analysis and evaluation remained individual categories, with evaluation leading to analysis in the model. Monitoring is not connected to the other metacognitive activities. Relational activities are also not connected to each other. Second, looking at the relations between sub-categories across the various main categories, the model shows that processing is bi-directionally connected to monitoring. Processing is also connected with evaluation, which in turn is connected to analysis. The relational activity support is located between analysis and reading and is bi-directionally connected to both. Finally, the model shows an isolated process with a bi-directional pathway between challenge and off-task activities in high challenge dyads. Summarizing, the verbal interactions of high challenge dyads can be characterized by a strong relation between processing and monitoring. In terms of the relational activities, support is related bidirectionally to both reading and analysis, whereas challenge shows an isolated process with off-task activities.
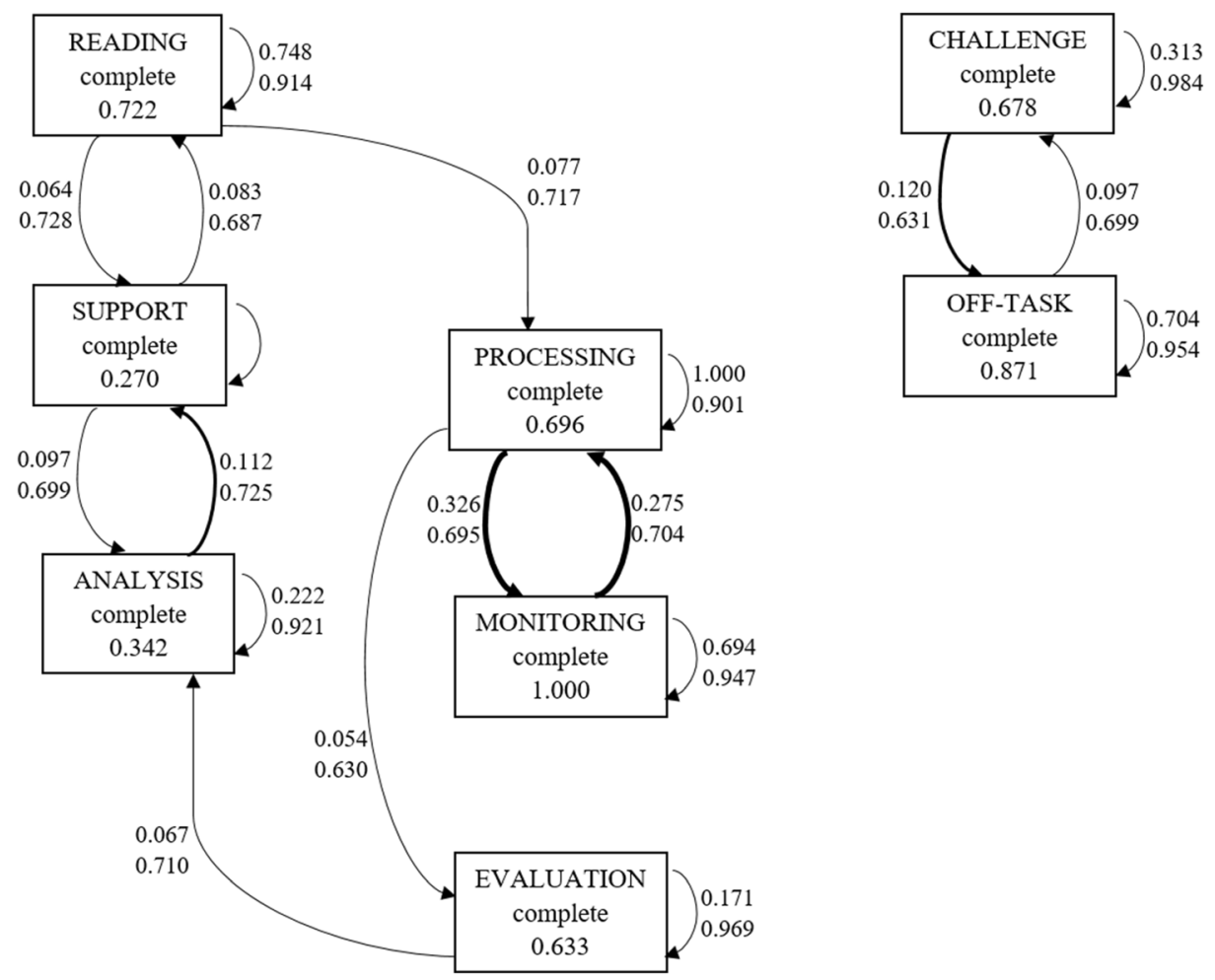

Fig. 2 Process model of high social challenge dyads. Numbers in the nodes represent the level of significance. Numbers on the edges represent the level of significance (top) and correlation (bottom) 


\section{Comparison of the process models}

A comparison of the process models of low and high social challenge dyads shows two similarities. First, both models contain a one-directional path from reading to processing that continues into a bi-directional path between processing and monitoring. Second, both models show a path from support to reading. However, for high challenge dyads this path is bi-directional, whereas for low challenge dyads it is onedirectional. The most important differences between the process models of low and high social challenge dyads are found in high-cognition, challenge, off-task activities, and the relations between metacognitive sub-categories. Only low challenge dyads shows high-cognition, which shows one-directional paths from reading, and to processing and support. On the other hand, only high challenge dyads shows off-task activities which is bi-directionally related to challenge. For low challenge dyads, these challenges shows a path from processing, and to analysis*evaluation. Notably, although challenge in low-challenge dyads was very infrequent, it has a high significance (0.726). Since the significance of events is established based on the frequency of their occurrence and their routing significance (i.e., its importance for directing the process to another activity), this finding indicates that the significance of challenge in low-challenge dyads was likely due to routing significance. Finally, another difference between the two models is the relation between metacognitive activities among each other and with support. For low challenge dyads, monitoring was bi-directionally related to an analysis*evaluation cluster, which, in turn, was one-directionally related to support. For high challenge dyads, however, monitoring was not related to the other metacognitive activities. Instead, the model showed a pathway from processing to evaluation, then on to analysis, and finally to a bi-directional path to support.

In order to illustrate the differences between the process models of high and low social challenge dyads, and to facilitate interpretation of these differences, transcript extracts are presented below. Because we distinguished the groups based on their level of social challenge, these transcripts will emphasize the position of challenge and support in the models.

Tables 3 and 4 show the effects of challenge in a low and high social challenge dyad respectively. For the low challenge dyad, the transcript (Table 3) starts with a discussion of the functions of capillaries when the dyad members try to describe them in their assignment. Lisa ${ }^{1}$ is writing and Emma is looking on. At the start of the sequence, Lisa is monitoring her content understanding, because she wants to ensure she understands the topic correctly: "Your cap, what was it again?; Capillaries, right?". She continues to whisper something to herself while she is typing. In the next turn, the collaboration process is threatened when Emma seems to disagree with the text Lisa is writing, and rejects Lisa's suggestion by saying "No". However, Emma immediately suggests an alternative action in her next turn, by referring to other sources that might help explain the functions of capillaries: "We could also browse some more, because there are two more sources". The challenge is resolved when Lisa agrees with Emma's planning activity and continues the sequence by reading new information "Yes.; The pulmonary circulation".

\footnotetext{
${ }^{1}$ All names are pseudonyms to protect anonymity
} 
In the high challenge dyad, the social challenge is not so easily resolved. In the example (Table 4), one dyad member (Mandy) tries to proceed with the learning assignment while the other dyad member (Jill) seems to be distracted and performs off-task activities. The conversation starts with Mandy's attempt to draw Jill's attention to the task: "Be, quiet now *...*", when they are watching a video. However, this attempt does not reach its goal as Jill performs off-task activities, by pretending to speak to the narrator of the video: "Do you want my number?; Five, two, *... *, Call me.; Five, two, three.". Subsequently, Jill's engagement in off-task activities triggers Mandy's second attempt to engage Jill in the topic: "No, stop. I should quickly *...*", but her second attempt also fails as Jill continues to ignore Mandy's attempts and continues to perform off-task activities: "Five, two, three.; Nine, two, seven, call me okay". This socially challenging situation seems to influence Mandy's approach to Jill's later turns because she starts rejecting her further utterances: "No, don't do that, alright?"; and "Not at all."

Summarizing, these two examples show some important differences between low and high challenge dyads. First, in the low challenge dyad the challenge is directly related to the task performance, whereas in the high challenge dyad the challenge is initially directed at the behaviour of the dyad partner, and only towards the end of the extract at the task performance. Second, in the low challenge dyad the dyad member who performs the challenge also immediately offers an alternative task approach, which provides an opportunity to resolve the challenge. In contrast, in the high challenge dyad, the challenge is not followed up by an alternative approach and is ignored by the dyad partner.

Tables 5 and 6 illustrate the position of support in a low and high social challenge dyad respectively. The transcript of low challenge dyads (Table 5) shows two consecutive examples of the sequence monitoring $\rightarrow$ analysis*evaluation $\rightarrow$ support, in which the second sequence continues into reading. In the example, the dyad is writing a passage about the importance of the heart and how one can keep it healthy. The first sequence starts with Lisa's metacognitive turn, in which she monitors how far they progressed with their task. She counts the number of words they wrote and tells how many more words they should write: "72, 3 more words". This leads Emma to control the dyad's plan by hinting a suggestion: "Shall we just start with the next one?". They reach agreement, because Emma's suggestion is being accepted by Lisa's "All right". This mutual agreement triggers the dyad's second sequence of monitoring $\rightarrow$ analysis*evaluation $\rightarrow$ support. Again, Lisa starts the sequence by monitoring the plan in detail: "Okay, and after that we should?", after which she proposes a new page to visit: "Your blood in the rollercoaster." At this point, the dyad reaches mutual agreement for the second time when Lisa's planning activity is approved by Emma's "Yes". Since both group members agree on the topic they want to focus on, Lisa ends the sequence by reading new information about the blood circulation in the human body: "Day and night, your heart pumps blood through your body". These sequences show that, in this low challenge dyad, support is used to reach mutual agreement and move the task forward.

The transcript of the high-challenge dyad (Table 6) shows an example of the bidirectional connection between analysis and support in high-challenge dyads. In the example, Tim and Max are trying to finish the passage they are working on, and the sequence starts with Tim's suggestion to copy the rest of the information from the Web page "Just copyit". Max approves Tim's suggestion "Yes" and Tim indicates which information is going to be copied: "All of it". For the second time, Max shows agreement with Tim and supports his idea "Yes.; Good 
plan.". This example shows that, while mutual agreement is also reached in this highchallenge dyad, it does not result in cognitive engagement with the learning material. Furthermore, the lack of any monitoring in the sequence, suggests that their planning activities are not strongly informed by their current task progress.

Summarizing, while both the low and high social challenge dyad used support to reach mutual agreement on a suggested plan, only the high social challenge dyad appeared to be able to base their plan on their current task progress and to follow up on their agreement with cognitive engagement.

\section{Discussion}

The present study investigated the extent to which low and high social challenge dyads differed in terms of the quality of their written assignment, as well as the frequency and sequential pattern of their cognitive, metacognitive, relational, and off-task activities during a collaborative hypermedia assignment. We first investigated the effect of social challenge on assignment quality. Results showed that, controlling for prior knowledge, assignment quality was higher for low challenge dyads. Second, we studied the effect of social challenge on the frequency of learning activities. Results showed that low challenge dyads showed more cognitive processing (low-cognition) and more high-cognition, whereas high challenge dyads showed more off-task activities. Finally, we investigated the effect of social challenge on the sequential patterns of learning activities. The process models of low and high challenge dyads showed marked differences. More specifically, the occurrence of high-cognition was only substantial enough for inclusion in the low-challenge model, whereas off-task activities only appeared in the highchallenge model. In the low challenge model, social challenges were positioned between cognitive processing and a cluster of metacognitive activities (analysis and evaluation). In addition, their monitoring was bi-directionally related to the other metacognitive activities, which in turn were a precursor for positive relational activities (support). In contrast, in the highchallenge model, social challenges were bi-directionally related to off-task activities in an isolated process. Additionally, their monitoring was not related to the other metacognitive activities, and only analysis showed a bi-directional relation to support.

\section{Social challenge in relation to assignment quality and frequencies of learning activities}

In support of the first hypothesis, low challenge dyads had higher assignment quality than high challenge dyads. This is in line with previous findings that indicated that negative interactions decreased problem solving success in high-school students (Chiu and Khoo 2003). As expected in the second hypothesis, low challenge dyads also had more high-cognition and fewer off-task activities. These results are in agreement with previous research which suggested that the content space and relational space of learning may compete for attention of the dyad (Barron 2003). The lower frequency of social challenges in the low challenge dyads may have given them the opportunity to spend more of their attention on engaging with the learning material. Furthermore, the large number of social challenges in the high challenge dyads may have triggered maladaptive emotion regulation strategies, such as avoidance-focused strategies (see also: Näykki et al. 2014). A finding not in line with the second hypothesis was that low and high challenge dyads did not differ in their number of metacognitive activities. Potentially, 
social challenges affect the quality rather than the quantity of metacognitive activities (see also: de Jong et al. 2005). In fact, previous research has shown that negative interactions lead to lower quality regulation (Rogat and Adams-Wiggins 2014), and may reduce collective task engagement (Bakhtiar et al. 2018).

\section{Social challenges in relation to sequential patterns of learning activities}

In terms of the sequential patterns, for which no a priori hypotheses were formulated, the process mining results show some similarities, but also marked differences between the learning process of low and high social challenge dyads. A similarity is that in both models, support showed a relation with low-cognition. This is in line with earlier research which showed that positive relational activities encouraged low-cognition (Molenaar and Chiu 2014). An important difference is the position of social challenges in the models. For low challenge dyads, they are positioned between processing and metacognitive activities, whereas for high challenge dyads, they were positioned in an isolated process together with off-task activities. The fact that for high challenge dyads off-task activities and social challenge were not connected to the rest of the learning process implies that there was no single most frequent antecedent to social challenge or off-task verbalisations. As such, no other activity in the model clearly triggered these activities. However, once the high challenge dyads displayed social challenge or off-task activities, it resulted in a relatively stable pattern, a vicious cycle, in which the two activities repeatedly followed each other. The fact that there is also no path from these two separate activities back to the larger process indicates there was no clear or frequently used route out of this cycle. This is in line with research that suggests that the occurrence of SSRL becomes less frequent once one member becomes disengaged (Isohätälä et al. 2017). As such, it appears to become difficult to re-enter the larger process that contains cognitive and metacognitive activities. For low challenge dyads, the social challenges were not part of an isolated process. Instead, they were sequentially embedded within cognitive and metacognitive activities. This pattern seems to be more in line with what is referred to as constructive conflict, during which there is an open atmosphere, dyad members seriously and critically consider each other's ideas, and differences in opinion can be resolved (van den Bossche et al. 2011). In low challenge dyads, therefore, cognitive processing appeared to trigger a conflict, after which the dyads used evaluation and planning activities to overcome their disagreement. This then allowed them to remain engaged with the task.

When comparing the results for the frequency analysis and the sequential analysis for metacognitive activities, the differences in the process models of low and high challenge dyads might explain the lack of frequency effects. High challenge dyads appeared to have been unable to follow up their monitoring with metacognitive control activities, such as planning or evaluation. Instead, low-cognition (processing) directly followed their monitoring. This may indicate that they could not sufficiently change their behaviour during the writing process when they encountered difficulties or became aware of a lack of understanding.

\section{Limitations}

This study has several limitations. First, the current study did not investigate why differences existed between dyads in terms of their level of social challenge during the collaboration. Previous research has suggested that several factors may affect group interactions, such peer status in the classroom (Murphy and Faulkner 2000, 2006), ability level (Denessen et al. 2008; 
Fuchs et al. 1998; Saleh et al. 2005), or non-verbal cues (Louwerse et al. 2012). While this study took into account prior knowledge in the analyses of the effect of social challenges on assignment quality, the measurement of prior knowledge was a simple declarative knowledge test. A more comprehensive assessment of prior knowledge, for example, by means of a concept mapping procedure, might have given more-detailed information. Future research could therefore investigate how such factors affect the sequential patterns of the verbal interactions of collaborating children.

A second limitation is that the results of the current study are shaped by the environment in which they were measured. Other hypermedia environments might show different collaborative interactions, and other coding schemes might result in different process models. Moreover, because the approach is descriptive in nature, caution is needed when these results are used for prediction or practical prescription (Reimann et al. 2014).

Finally, a third limitation is that the current study could not assess SSRL directly. SSRL is often coded at the level of episodes, rather than individual codes (e.g., Grau and Whitebread 2012; Iiskala et al. 2011; Khosa and Volet 2014; Volet et al. 2009). Capturing SSRL in a process model would therefore result in too great a loss of information about the individual cognitive and metacognitive activities in the learning process. Consequently, however, the study could not differentiate between the different forms of regulation (self-, co-, or shared).

\section{Theoretical implications and suggestions for future research}

This study has implications for the field of SSRL and metacognition, and leads to several suggestions for future research. An important implication of this research lies in the differences in results between the frequency analyses and process mining. The results suggest that studying sequences provides additional insight into group differences. More specifically, process mining enabled us to observe how dyads who differed in their level of challenge responded to challenges during the collaboration and how they used metacognitive activities. As such, process mining may be an alternative way to investigate the qualitative aspect of learning activities based on their relationships to each other, as opposed to a more qualitative approach, in which the quality of activities is coded. Naturally, future research should explore the comparability of a qualitative coding approach and a process mining approach.

In terms of the suggestions for future research, the transcripts showed that collaborating dyads with fewer social challenges were able to follow up on their challenges with a plan for an alternative approach, which appears to indicate a strategy for conflict resolution (Hadwin et al. 2011). This was not the case for dyads with more frequent social challenges. However, because this difference stems from transcript examples, it is unclear to which extent it generalized to the entire sample. Future research could test this empirically, by investigating how training children to use metacognitive planning and evaluation activities after a disagreement affects the over learning process and assignment quality. In addition, the current findings on conflict resolution could be compared to a more direct assessment, in which the data is coded at an episodic level, with specific attention to conflicts and conflict resolution.

Second, process mining provides a description of the process in terms of sequences of events. It should be acknowledged, however, that the quality of individual learning activities consists of more than their sequential position in the overall process. Future research may also include other assessments of the quality of the activities, such as coding the quality of activities at the utterance level, or adding a layer of coding at the level of episodes in order to capture the 
socially shared nature of the activities. In addition, process mining does not capture all aspects of the quality of the learning process, because it does not take into account non-linear changes that might occur during a learning process. For example, a group member's contribution may act as a moment in time from which onwards the nature of the process fundamentally changes (see e.g., Wise and Chiu 2011). Such a (sudden) change in the process is also referred to as a phase transition (Spivey et al. 2009). While the assumption of linearity of change is often made in the social sciences, non-linear change may actually be an important characteristic of development and change in a complex and open system such as humans are (Jacobson et al. 2016; Reimann et al. 2014; van Geert 2011). Future research could therefore investigate the extent to which, and under what conditions, social challenges bring about fundamental changes in the learning process of children.

Finally, this study investigated the effect of social challenge in dyads. Since interaction patterns are likely to be different in groups compared to dyads (Moreland 2010), the effects of social challenge on the learning process may likely also be different in groups. Therefore, future research will need to establish the extent to which the present findings transfer to group settings.

\section{Practical implications}

Although practical implications based on process models should be made with caution (Reimann et al. 2014), the results of the sequential analyses show that not only frequencies of social challenges matter, but that one can also differentiate between challenges that are successfully resolved, and challenges that require the involvement of a teacher to help the dyad get back on task. More specifically, teachers may be able to recognize maladaptive social challenges more adequately by paying attention to how learners respond to the social challenges that occur. Based on the differences between the process models, it appears that not all social challenges require an equal amount of teacher interference. Moreover, teachers can be alerted to off-task transitions after a social challenge occurred which may be indicative of ineffective conflict resolution in the dyad. Finally, instances of monitoring that are not followed up by either evaluation or control activities may be guided by teachers to become more productive.

\section{Conclusion}

To conclude, the present study showed that repeated occurrences of social challenge during collaboration have a negative effect on learning outcomes and result in changes in the overall learning process. Those pairs with fewer social challenges showed more cognitive processing activities, more high-cognition, and fewer off-task activities. Their metacognitive activities were closely connected to each other in the learning process. However, pairs with more social challenges, and who therefore repeatedly have disagreements, may be at risk for lower assignment quality. They are more easily distracted, more easily go off-topic, and have trouble getting back on-topic once they enter a vicious cycle of off-topic verbalizations and negativity.

\section{Compliance with ethical standards}

Conflict of interest The authors declare that they have no conflict of interest. 


\section{Appendix}

Table 7 Absolute frequencies of original categories of verbal interactions for low- and high-challenge dyads

\begin{tabular}{|c|c|c|c|c|c|c|c|c|}
\hline & \multicolumn{4}{|c|}{ Low challenge $(n=18)$} & \multicolumn{4}{|c|}{ High challenge $(n=12)$} \\
\hline & Min & $\operatorname{Max}$ & $\mathrm{M}$ & $\mathrm{SD}$ & Min & Max & M & SD \\
\hline \multicolumn{9}{|l|}{ Cognition } \\
\hline Reading & 19 & 198 & 80.50 & 57.13 & 4 & 167 & 66.33 & 44.19 \\
\hline Processing & 7 & 394 & 139.28 & 114.47 & 17 & 193 & 93.75 & 42.16 \\
\hline High-cognition: summarizing & 0 & 38 & 6.39 & 10.06 & 0 & 10 & 2.50 & 2.94 \\
\hline High-cognition: elaboration & 0 & 44 & 11.94 & 13.65 & 0 & 15 & 5.58 & 4.98 \\
\hline High-cognition: questioning & 0 & 10 & 3 & 2.95 & 0 & 5 & 2.25 & 1.60 \\
\hline \multicolumn{9}{|l|}{ Metacognition } \\
\hline Analysis: orientation & 0 & 7 & 2.94 & 2.92 & 0 & 13 & 5.00 & 4.37 \\
\hline Analysis: planning & 4 & 71 & 31.89 & 14.82 & 7 & 43 & 30.00 & 10.30 \\
\hline Monitoring & 27 & 241 & 95.44 & 56.62 & 45 & 186 & 104.33 & 38.03 \\
\hline Evaluation: Evaluation & 1 & 28 & 12.00 & 6.61 & 5 & 29 & 13.25 & 8.41 \\
\hline Evaluation: Reflection & 0 & 11 & 1.56 & 2.94 & 0 & 5 & 1.75 & 2.05 \\
\hline \multicolumn{9}{|l|}{ Relational } \\
\hline Challenge: Rejection & 0 & 27 & 7.61 & 6.27 & 9 & 45 & 26.33 & 10.03 \\
\hline Challenge: Engagement & 0 & 9 & 3.78 & 2.82 & 2 & 45 & 15.33 & 13.23 \\
\hline Support & 0 & 59 & 31.28 & 16.33 & 7 & 40 & 24.00 & 11.12 \\
\hline Task division & 0 & 19 & 6.78 & 5.20 & 2 & 26 & 12.08 & 7.03 \\
\hline \multicolumn{9}{|l|}{ Other } \\
\hline Off-task & 1 & 77 & 21.50 & 24.83 & 8 & 136 & 49.67 & 34.96 \\
\hline
\end{tabular}

Open Access This article is distributed under the terms of the Creative Commons Attribution 4.0 International License (http://creativecommons.org/licenses/by/4.0/), which permits unrestricted use, distribution, and reproduction in any medium, provided you give appropriate credit to the original author(s) and the source, provide a link to the Creative Commons license, and indicate if changes were made.

\section{References}

Azevedo, R. (2005). Using hypermedia as a metacognitive tool for enhancing student learning? The role of self-regulated learning. Educational Psychologist, 40(4), 199-209. https://doi.org/10.1207 /s15326985ep4004 2.

Azevedo, R., \& Cromley, J. G. (2004). Does training on self-regulated learning facilitate students' learning with hypermedia? Journal of Educational Psychology, 96(3), 523-535. https://doi.org/10.1037/00220663.96.3.523.

Bakhtiar, A., Webster, E. A., \& Hadwin, A. F. (2018). Regulation and socio-emotional interactions in a positive and a negative group climate. Metacognition and Learning, 13(1), 57-90. https://doi.org/10.1007/s11409017-9178-x.

Bannert, M., Reimann, P., \& Sonnenberg, C. (2014). Process mining techniques for analysing patterns and strategies in students' self-regulated learning. Metacognition and Learning, 9(2), 161-185. https://oi. org/10.1007/s11409-013-9107-6.

Barron, B. (2003). When smart groups fail. Journal of the Learning Sciences, 12(3), 307-359. https://doi. org/10.1207/S15327809JLS1203 1.

Chiu, M. M., \& Fujita, N. (2014). Statistical discourse analysis: a method for modeling online discussion processes. Journal of Learning Analytics, 1(3), 61-83 Retrieved from http://epress.lib.uts.edu. au/journals/index.php/JLA/article/view/4074.

Chiu, M. M., \& Khoo, L. (2003). Rudeness and status effects during group problem solving: Do they bias evaluations and reduce the likelihood of correct solutions? Journal of Educational Psychology, 95(3), 506523. https://doi.org/10.1037/0022-0663.95.3.506. 
de Jong, F., Kollöffel, B., van der Meijden, H., Staarman, J. K., \& Janssen, J. (2005). Regulative processes in individual, 3D and computer supported cooperative learning contexts. Computers in Human Behavior, 21(4), 645-670. https://doi.org/10.1016/j.chb.2004.10.023.

Denessen, E., Veenman, S., Dobbelsteen, J., \& Van Schilt, J. (2008). Dyad composition effects on cognitive elaboration and student achievement. The Journal of Experimental Education, 76(4), 363-386. https://doi.org/10.3200/JEXE.76.4.363-386.

Fuchs, L. S., Fuchs, D., Hamlett, C. L., \& Karns, K. (1998). High-achieving students' interactions and performance on complex mathematical tasks as a function of homogeneous and heterogeneous pairings. American Educational Research Journal, 35(2), 227-267. https://doi.org/10.3102/00028312035002227.

Goos, M., Galbraith, P., \& Renshaw, P. (2002). Socially mediated metacognition: Creating collaborative zones of proximal development in small group problem solving. Educational Studies in Mathematics, 49(2), 193-223.

Grau, V., \& Whitebread, D. (2012). Self and social regulation of learning during collaborative activities in the classroom: The interplay of individual and group cognition. Learning and Instruction, 22(6), 401-412. https://doi.org/10.1016/j.learninstruc.2012.03.003.

Greene, J. A., Moos, D. C., \& Azevedo, R. (2011). Self-regulation of learning with computer-based learning environments. New Directions for Teaching and Learning, 126, 107-115. https://doi.org/10.1002/tl.449.

Günther, C. W., \& van der Aalst, W. M. P. (2007). Fuzzy mining - Adaptive process simplification based on multi-perspective metrics. In International conference on business process management (pp. 328-343). Berlin, Heidelberg: Springer. https://doi.org/10.1007/978-3-540-75183-0 24.

Hadwin, A. F., Järvelä, S., \& Miller, M. (2011). Self-regulated, co-regulated, and socially shared regulation of learning. In Handbook of self-regulation of learning and performance (30th ed., pp. 65-84). https://doi. org/10.4324/9780203839010.ch5

Iiskala, T., Vauras, M., Lehtinen, E., \& Salonen, P. (2011). Socially shared metacognition of dyads of pupils in collaborative mathematical problem-solving processes. Learning and Instruction, 21(3), 379-393. https://doi.org/10.1016/j.learninstruc.2010.05.002.

Isohätälä, J., Järvenoja, H., \& Järvelä, S. (2017). Socially shared regulation of learning and participation in social interaction in collaborative learning. International Journal of Educational Research, 81, 11-24. https:/doi. org/10.1016/j.ijer.2016.10.006.

Jacobson, M. J., Kapur, M., \& Reimann, P. (2016). Conceptualizing debates in learning and educational research: Toward a complex systems conceptual framework of learning. Educational Psychologist, 51(2), 210-218. https://doi.org/10.1080/00461520.2016.1166963.

Janssen, J., Erkens, G., Kirschner, P. A., \& Kanselaar, G. (2012). Task-related and social regulation during online collaborative learning. Metacognition and Learning, 7(1), 25-43. https://doi.org/10.1007/s11409-010-9061-5.

Järvelä, S., \& Hadwin, A. F. (2013). New frontiers: Regulating learning in CSCL. Educational Psychologist, 48(1), 25-39. https://doi.org/10.1080/00461520.2012.748006.

Järvelä, S., Malmberg, J., \& Koivuniemi, M. (2016). Recognizing socially shared regulation by using the temporal sequences of online chat and logs in CSCL. Learning and Instruction, 42, 1-11. https://doi. org/10.1016/j.learninstruc.2015.10.006.

Järvenoja, H., \& Järvelä, S. (2009). Emotion control in collaborative learning situations: Do students regulate emotions evoked by social challenges? British Journal of Educational Psychology, 79(3), 463-481. https://doi.org/10.1348/000709909X402811.

Khosa, D. K., \& Volet, S. E. (2014). Productive group engagement in cognitive activity and metacognitive regulation during collaborative learning: Can it explain differences in students' conceptual understanding? Metacognition and Learning, 9(3), 287-307. https://doi.org/10.1007/s11409-014-9117-z.

King, A. (2002). Structuring peer interaction to promote high-level cognitive processing. Theory Into Practice, 41(1), 33-39. https://doi.org/10.1207/s15430421tip4101_6.

Kinnebrew, J. S., Segedy, J. R., \& Biswas, G. (2014). Analyzing the temporal evolution of students' behaviors in open-ended learning environments. Metacognition and Learning, 9(2), 187-215. https://doi.org/10.1007 /s11409-014-9112-4.

Kirschner, P. A., \& Erkens, G. (2013). Toward a framework for CSCL research. Educational Psychologist, 48(1), 1-8. https://doi.org/10.1080/00461520.2012.750227.

Kreijins, K., Kirschner, P. A., \& Jochems, W. (2003). Identifying the pitfalls for social interaction in computersupported collaborative learning environments: a review of the research. Computers in Human Behaviour, 19(3), 335-353.

Kreijns, K., Kirschner, P. A., \& Jochems, W. (2002). The sociability of computer-supported collaborative learning environmnets. Educational Technology and Society, 5(1), 8-22.

Kreijns, K., Kirschner, P. A., \& Vermeulen, M. (2013). Social aspects of CSCL environments: a research framework. Educational Psychologist, 48(4), 229-242. https://doi.org/10.1080/00461520.2012.750225. 
Levine, J. M., \& Resnick, L. B. (1993). Social foundations of cognition. Annual Review of Psychology, 44, 585-612.

Louwerse, M. M., Dale, R., Bard, E. G., \& Jeuniaux, P. (2012). Behavior matching in multimodal communication is synchronized. Cognitive Science, 36(8), 1404-1426. https://doi.org/10.1111/j.1551-6709.2012.01269.x.

Meijer, J., Veenman, M. V. J., Hout-Wolters, V., \& B. H. a. M. (2006). Metacognitive activities in text-studying and problem-solving: Development of a taxonomy. Educational Research and Evaluation, 12(3), $209-237$. https://doi.org/10.1080/13803610500479991.

Molenaar, I., \& Chiu, M. M. (2014). Dissecting sequences of regulation and cognition: Statistical discourse analysis of primary school children's collaborative learning. Metacognition and Learning, 9(2), 137-160. https://doi.org/10.1007/s11409-013-9105-8.

Molenaar, I., \& Chiu, M. M. (2017). Effects of sequences of cognitions on group performance over time. Small Group Research, 48(2), 131-164. https://doi.org/10.1177/1046496416689710.

Molenaar, I., \& Järvelä, S. (2014). Sequential and temporal characteristics of self and socially regulated learning. Metacognition and Learning, 9(2), 75-85. https://doi.org/10.1007/s11409-014-9114-2.

Molenaar, I., Chiu, M. M., Sleegers, P., \& Boxtel, C. van. (2011). Scaffolding of small groups' metacognitive activities with an avatar. Computer-Supported Collaborative Learning, 6, 601-624. https://doi.org/10.1007 /s11412-011-9130-z.

Moreland, R. L. (2010). Are dyads really groups? Small Group Research, 41(2), 251-267. https://doi. org/10.1177/1046496409358618.

Murphy, S. M., \& Faulkner, D. (2000). Learning to collaborate: Can young children develop better communication strategies through collaboration with a more popular peer. European Journal of Psychology of Education, 15(4), 389-404. https://doi.org/10.1007/BF03172983.

Murphy, S. M., \& Faulkner, D. (2006). Gender differences in verbal communication between popular and unpopular children during an interactive task. Social Development, 15(1), 82-108. https://doi.org/10.1111 j.1467-9507.2006.00331.x.

Näykki, P., Järvelä, S., Kirschner, P. A., \& Järvenoja, H. (2014). Socio-emotional conflict in collaborative learning - a process-oriented case study in a higher education context. International Journal of Educational Research, 68, 1-14. https://doi.org/10.1016/j.ijer.2014.07.001.

Paans, C., Molenaar, I., Segers, E., \& Verhoeven, L. (2018). Temporal variation in children's self-regulated hypermedia learning. Computers in Human Behavior, 1-13. https://doi.org/10.1016/j.chb.2018.04.002.

Paans, C., Segers, E., Molenaar, I., \& Verhoeven, L. (2019). Dyadic executive function effects in children's collaborative hypermedia learning. Learning and Instruction, 60, 66-74. https://doi.org/10.1016/j. learninstruc.2018.11.008

Panadero, E., \& Järvelä, S. (2015). Socially shared regulation of learning: a review. European Psychologist, 20(3), 190-203. https://doi.org/10.1027/1016-9040/a000226.

Reimann, P. (2009). Time is precious: Variable- and event-centred approaches to process analysis in CSCL research. International Journal of Computer-Supported Collaborative Learning, 4(3), 239-257. https://doi. org/10.1007/s11412-009-9070-z.

Reimann, P., Markauskaite, L., \& Bannert, M. (2014). E-research and learning theory: What do sequence and process mining methods contribute? British Journal of Educational Technology, 45(3), 528-540. https://doi. org/10.1111/bjet.12146.

Rogat, T. K., \& Adams-Wiggins, K. R. (2014). Other-regulation in collaborative groups: Implications for regulation quality. Instructional Science, 42(6), 879-904. https://doi.org/10.1007/s11251-014-9322-9.

Rogat, T. K., \& Adams-Wiggins, K. R. (2015). Interrelation between regulatory and socioemotional processes within collaborative groups characterized by facilitative and directive other-regulation. Computers in Human Behavior, 52, 589-600. https://doi.org/10.1016/j.chb.2015.01.026.

Rogat, T. K., \& Linnenbrink-Garcia, L. (2011). Socially shared regulation in collaborative groups: An analysis of the interplay between quality of social regulation and group processes. Cognition and Instruction, 29(4), 375-415. https://doi.org/10.1080/07370008.2011.607930.

Roy, A. W. N., \& Howe, C. J. (1990). Effects of cognitive conflict, socio-cognitive conflict and imitation on children's socio-legal thinking. European Journal of Social Psychology, 20(3), 241-252. https://doi. org/10.1002/ejsp.2420200305.

Saleh, M., Lazonder, A., \& de Jong, T. (2005). Effects of within-class ability grouping on social interaction, achievement, and motivation. Instructional Science, 33(2), 105-119. https://doi.org/10.1007/s11251-0046405-z.

Salonen, P., Vauras, M., \& Efklides, A. (2005). Social interaction - what can it tell us about metacognition and coregulation in learning? European Psychologist, 10(3), 199-208. https://oi.org/10.1027/10169040.10.3.199. 
Schoor, C., \& Bannert, M. (2012). Exploring regulatory processes during a computer-supported collaborative learning task using process mining. Computers in Human Behavior, 28(4), 1321-1331. https://doi. org/10.1016/j.chb.2012.02.016.

Segers, E., \& Verhoeven, L. (2009). Learning in a sheltered internet environment: The use of WebQuests. Learning and Instruction, 19(5), 423-432. https://doi.org/10.1016/j.learninstruc.2009.02.017.

Slof, B., Erkens, G., Kirschner, P. A., Jaspers, J. G. M., \& Janssen, J. (2010). Guiding students’ online complex learning-task behavior through representational scripting. Computers in Human Behavior, 26(5), 927-939. https://doi.org/10.1016/j.chb.2010.02.007.

Sobocinski, M., Malmberg, J., \& Järvelä, S. (2017). Exploring temporal sequences of regulatory phases and associated interactions in low- and high-challenge collaborative learning sessions. Metacognition and Learning, 12(2), 275-294. https://doi.org/10.1007/s11409-016-9167-5.

Spivey, M. J., Anderson, S. E., \& Dale, R. (2009). The phase transition in human cognition. New Mathematics and Natural Computation, 05(1), 197-220. https://doi.org/10.1142/S1793005709001234.

Tudge, J. R. H. (1989). When collaboration leads to regression: Some negative consequences of socio-cognitive conflict. European Journal of Social Psychology, 19(2), 123-138. https://doi.org/10.1002/ejsp.2420190204.

Tudge, J. R. H. (1992). Processes and consequences collaboration: a Vygotskian of peer analysis. Child Development, 63(6), 1364-1379.

Ucan, S., \& Webb, M. (2015). Social regulation of learning during collaborative inquiry learning in science: How does it emerge and what are its functions? International Journal of Science Education, 37(15), 2503-2532. https://doi.org/10.1080/09500693.2015.1083634.

Van den Bossche, P., Gijselaers, W. H., Segers, M., \& Kirschner, P. A. (2006). Social and cognitive factors driving teamwork in collaborative learning environments. Small Group Research, 37(5), 490-521. https://doi.org/10.1177/1046496406292938.

van den Bossche, P., Gijselaers, W., Segers, M., Woltjer, G., \& Kirschner, P. (2011). Team learning: Building shared mental models. Instructional Science, 39(3), 283-301. https://doi.org/10.1007/s11251-010-9128-3.

van Geert, P. L. C. (2011). The contribution of complex dynamic systems to development. Child Development Perspectives, 5(4), 273-278. https://doi.org/10.1111/j.1750-8606.2011.00197.x.

Veenman, M. V. J., Van Hout-Wolters, B. H. A. M., \& Afflerbach, P. (2006). Metacognition and learning: Conceptual and methodological considerations. Metacognition and Learning, 1(1), 3-14. https://oi. org/10.1007/s11409-006-6893-0.

Volet, S. E., Summers, M., \& Thurman, J. (2009). High-level co-regulation in collaborative learning: How does it emerge and how is it sustained? Learning and Instruction, 19(2), 128-143. https://doi.org/10.1016/j. learninstruc.2008.03.001.

Wise, A. F., \& Chiu, M. M. (2011). Analyzing temporal patterns of knowledge construction in a role-based online discussion. International Journal of Computer-Supported Collaborative Learning, 6(3), 445-470. https://doi.org/10.1007/s11412-011-9120-1.

Zimmerman, B. J. (2002). Becoming a self-regulated learner: An overview. Theory Into Practice, 41(2), 64-70. https://doi.org/10.1207/s15430421 tip4102_2.

Publisher's note Springer Nature remains neutral with regard to jurisdictional claims in published maps and institutional affiliations. 